\title{
Preparation of Nanostructured Fluorine Doped Tin Oxide (FTO) by Hydrothermal Method
}

\author{
Asyikin Sasha Mohd Hanif ${ }^{1, a}$, Lau Weng Kuen ${ }^{1, b}$, Fariza Mohamad ${ }^{1, c}$, \\ Wan Suhaimizan Wan Zaki ${ }^{1, d}$, and Mohd Khairul Ahmad ${ }^{1, e}$ \\ ${ }^{1}$ Microelectronic and Nanotechnology - Shamsuddin Research Centre (Mint-SRC), Universiti Tun \\ Hussein Onn Malaysia, Parit Raja, 86400, Batu Pahat, Johor, Malaysia \\ aasyikinsasha@gmail.com, bae100186@siswa.uthm.edu.my, 'cfarizamd@uthm.edu.my \\ dmizan@uthm.edu.my, eakhairul@uthm.edu.my
}

Keywords: Nanostructure, Fluorine Doped Tin Oxide, Hydrothermal, DBTA.

\begin{abstract}
This study demonstrates the fabrication of nanostructured FTO by hydrothermal method. It was directly synthesized on FTO glass substrate by using pentahydrate stannic chloride $\left(\mathrm{SnCl}_{4} .5 \mathrm{H}_{2} \mathrm{O}\right)$ and ammonium fluoride $\left(\mathrm{NH}_{4} \mathrm{~F}\right)$ as precursors. Different synthesis time was applied which were $5 \mathrm{~h}, 10 \mathrm{~h}$ and $24 \mathrm{~h}$. The characteristics of nanostructured FTO were investigated via field emission scanning electron microscopy (FESEM), two-point probe current-voltage test and ultraviolet visible spectrometer (UV-Vis). The FESEM images revealed the growth of nano-sized particles layer on the FTO substrate. The electrical properties studied have shown a degeneration of conductivity as the thickness of nanostructured layer increased. UV-Vis results showed the decrement of transmittance as the time duration increased. It was revealed through FESEM characterization that the nanostructured FTO can be improved by using dibutyltin diacetate (DBTA) as a precursor.
\end{abstract}

\section{Introduction}

Transparent conducting oxides (TCO) have been extensively studied over the past decades due to its wide band gap which improvised the high optical transmittance (up to 90\%) with low electrical resistivity (i.e. few times $10^{-4} \Omega \mathrm{cm}$ ), low thermal emittance and high infrared reflectivity [1-2]. There are a number of diverse applications of transparent conducting oxides in thin film technology including liquid crystal displays, thick film sensors, transparent electrodes in solar cells, flat panel displays, organic light emitting diodes and heat mirrors [3]. It has been reported, tin oxide $\left(\mathrm{SnO}_{2}\right)$ thin film is one of the elements in TCO family which is transparent in the visible region and have high infrared reflectivity. Across the groups III, V, VI and VII elements of the periodic table, $\mathrm{SnO}_{2}$ thin film can be doped with dopants such as tin doped indium oxide, $\operatorname{In}_{2} \mathrm{O}_{3}: \mathrm{Sn}$ (ITO), fluorine doped tin oxide, $\mathrm{SnO}_{2}: \mathrm{F}$ (FTO), antimony doped tin oxide, $\mathrm{SnO}_{2}: \mathrm{Sb}$ (ATO), aluminum doped zinc oxide, $\mathrm{ZnO}: \mathrm{Al}$ (AZO) and gallium doped zinc oxide, $\mathrm{ZnO}: \mathrm{Ga}(\mathrm{GZO})$. Among the elements mentioned, FTO thin film is the most frequently used dopant where it can be exhibited stably both thermally and chemically with high optical transparency in visible range and high electrical conductivity [45]. FTO thin film is a versatile n-type group VII semiconductor with its excellent properties for applications in solar cell window layers [6], gas sensor devices [7], substrates for electrodeposition [8], and transparent contact in optoelectronic devices and etc.

In this context, size control of the nano-scale is essential where the nanostructured FTO requires special attention relative to structural, optical and electrical properties. For instance, when a nanorod array grew on the seed layer, the nanorod is directly related to the nanoparticle size of the seed layer [9]. Various methods to prepare FTO has been reported which include sol-gel and spray pyrolysis deposition (SPD) [10], dc and rf sputtering [11], pulsed laser deposition [12], and chemical vapour deposition [13]. The properties of nanostructured FTO are relatively affected by the hydrothermal method as well as the experimental parameters. From previous studies, it was determined that the solution-based method offers low cost production, simple and high growth rate of seed layer on the nanostructured FTO compared to the amorphous method. For instance, the 
hydrothermal process of growing $\mathrm{ZnO}$ nanostructures has gained immense popularity due to its simplicity and tolerable growth conditions [14]. Liu and Aydil [15] has found a simple hydrothermal method for growing oriented single crystalline rutile $\mathrm{TiO}_{2}$ nanorods on FTO substrates. When comparing to other techniques, hydrothermal method is a good candidate for the fabrication of nanostructured FTO thin film. Throughout the decades, various FTO nanostructures had been reported such as nanorods, nanobows, nanobelts and nanocages which exhibited different properties.

With these information, we made an attempt to prepare nanostructured FTO film for higher conductivity, higher optical transparency and low resistivity via hydrothermal method. This study focuses on the behavior of nanostructured FTO thin film in terms of structural, morphological and optical properties.

\section{Experimental}

The nanostructured FTO thin film was fabricated by hydrothermal method from the solution with the mixture of precursors pentahydrate stannic chloride $\left(\mathrm{SnCl}_{4} .5 \mathrm{H}_{2} \mathrm{O}\right)$, ammonium fluoride $\left(\mathrm{NH}_{4} \mathrm{~F}\right)$ and 2-propanol. $\mathrm{SnCl}_{4} .5 \mathrm{H}_{2} \mathrm{O}$ and $\mathrm{NH}_{4} \mathrm{~F}$ were dissolved separately in $30 \mathrm{ml}$ of distilled water and both dissolved solution were stirred for 20 minutes. Then, they were mixed together and $30 \mathrm{ml}$ of $2-$ propanol was added. The solution was stirred for another 20 minutes.

Prior to the solution preparation, FTO glass substrate with dimension $2.5 \mathrm{~cm} \times 1.0 \mathrm{~cm}$ was cleaned using ultrasonicator in a solution containing $10 \mathrm{ml}$ of acetone $\left(\left(\mathrm{CH}_{3}\right)_{2} \mathrm{CO}\right), 10 \mathrm{ml}$ of distilled water and $10 \mathrm{ml}$ of propanol. The cleaning process was done at temperature $28{ }^{\circ} \mathrm{C}$ for 10 minutes. The FTO glass substrate was then put onto sample stage which was earlier put in the Teflon-lined stainless autoclave tube filled with $90 \mathrm{ml}$ of the prepared solution. The tube was put into the forced convection oven at temperature $150{ }^{\circ} \mathrm{C}$ for $5 \mathrm{~h}$. This process was repeated for various time duration which were 10 and $24 \mathrm{~h}$. After the synthesis process, the glass substrate was taken out and rinsed extensively with deionized water and lastly, dried at $60{ }^{\circ} \mathrm{C}$ in ambient air

The samples were characterized for their morphological, electrical and optical properties via field-emission scanning electron microscopy (JEOL, Model: JSM-7600F), two-point probe I-V measurement (KEITHLY, Model: Series 2400 SourceMeter) and UV-Vis spectrometer (Shimadzu, Model: UV 1800), respectively.

\section{Results and Discussion}

\section{A. Morphological characterization}

Fig. 1, Fig. 2 and Fig. 3 depicted the FESEM images of nanostructured FTO thin film fabricated for $5 \mathrm{~h}, 10 \mathrm{~h}$ and $24 \mathrm{~h}$, respectively. It can be seen that the grain size and its distribution were greatly influenced by the synthesis time duration where the grain size increased when the time duration increased. At $5 \mathrm{~h}$, the layer of nanoparticles grew on top of FTO glass substrate surface with the smallest mean grain size of $310 \mathrm{~nm}$ and average thickness of $1046 \mathrm{~nm}$. At $10 \mathrm{~h}$, the mean grain size increased 1.5 times to about $465 \mathrm{~nm}$ and the thickness increased to $1133 \mathrm{~nm}$. While for $24 \mathrm{~h}$, the grain size was the largest among the three time duration which was $500 \mathrm{~nm}$ and thickness of $3857 \mathrm{~nm}$.

Grain size and its distribution greatly affected the surface area and grain boundaries of the nanostructured FTO thin film. As lesser grain boundaries can cause larger conductivity and higher electron density, the lowest grain boundaries can be obtained by having the largest grain distribution. From FESEM images, 5h sample fulfilled this requirement. However, there were numbers of irregular grains, compact structures and different shapes at three different time duration. Another fabrication was done where $0.8 \mathrm{M}$ dibutyltin diacetate (DBTA) was dissolved in ethyl alcohol solution and $1.53 \mathrm{M} \mathrm{NH}_{4} \mathrm{~F}$ dissolved in $90 \%$ water solution with $10 \%$ ethyl alcohol solution. FESEM images in Fig. 4 showed a more regular, small nanocrystal growth scattered on the FTO crystals. From morphological observations, hydrothermal using DBTA solution may exhibit higher potential for optimize performance of nanostructured FTO thin film. 

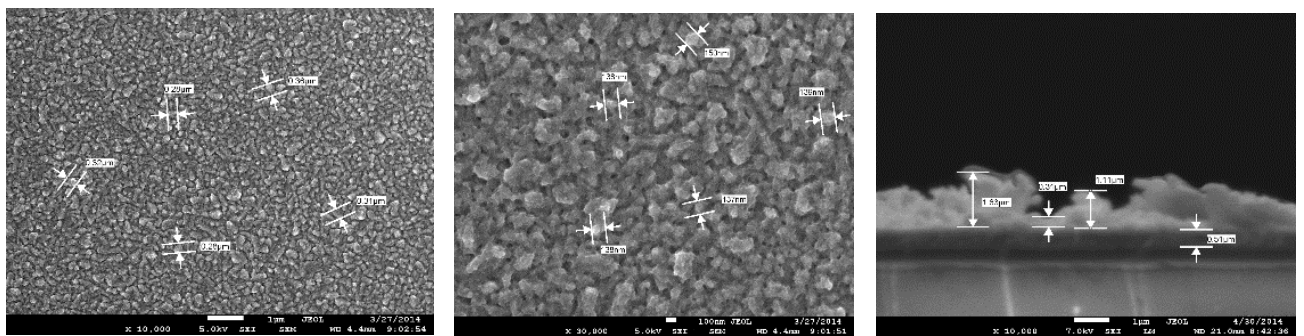

Figure 1: FESEM images of $5 \mathrm{~h}$ nanostructured FTO thin film grown on FTO substrate (left-right) top view at $10 \mathrm{k}$ magnification, top view at 30k magnification, cross-section view.
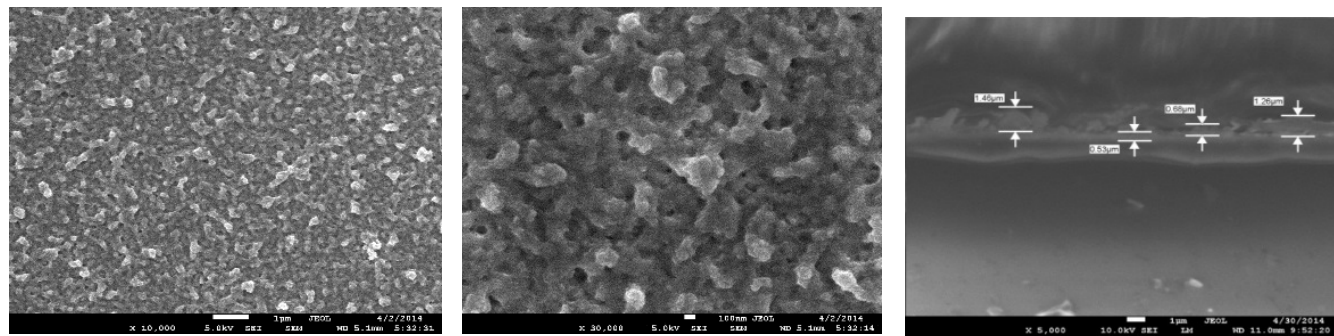

Figure 2: FESEM images of $10 \mathrm{~h}$ nanostructured FTO thin film grown on FTO substrate (left-right) top view at $10 \mathrm{k}$ magnification, top view at 30k magnification, cross-section view.
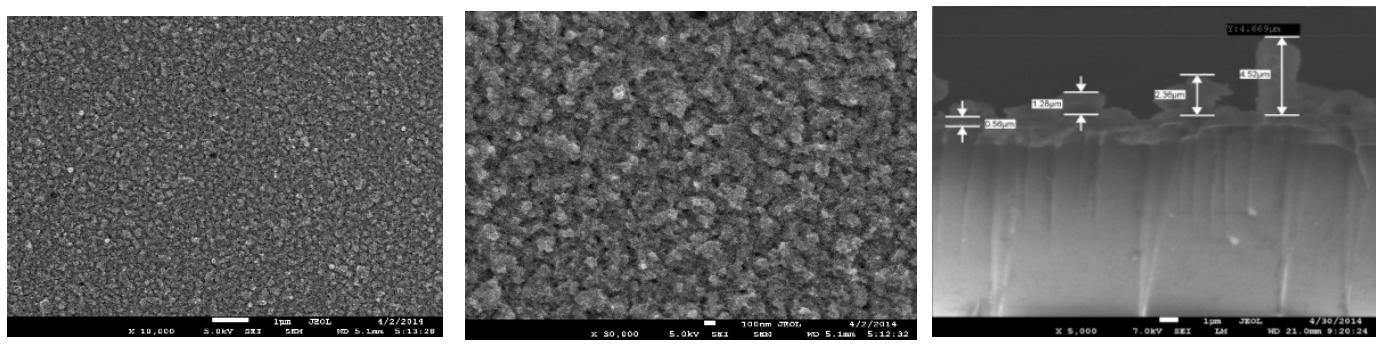

Figure 3: FESEM images of $24 \mathrm{~h}$ nanostructured FTO thin film grown on FTO substrate (left-right) top view at $10 \mathrm{k}$ magnification, top view at 30k magnification, cross-section view.
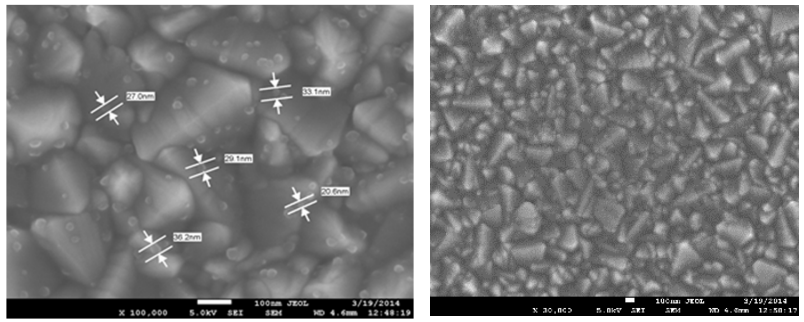

Figure 4: FESEM images of $5 \mathrm{~h}$ nanostructured FTO by DBTA (left) top view at $10 \mathrm{k}$ magnification, (right) top view at $30 \mathrm{k}$ magnification.

\section{B. Electrical properties}

The variation of current versus voltage of nanostructured FTO thin film from $-5 \mathrm{~V}$ to $5 \mathrm{~V}$ at different time duration of hydrothermal synthesis was shown in Fig. 5. There were shift of I-V gradient among the three different time duration where the $5 \mathrm{~h}$ sample has the highest gradient, followed by $10 \mathrm{~h}$ and then $24 \mathrm{~h}$.

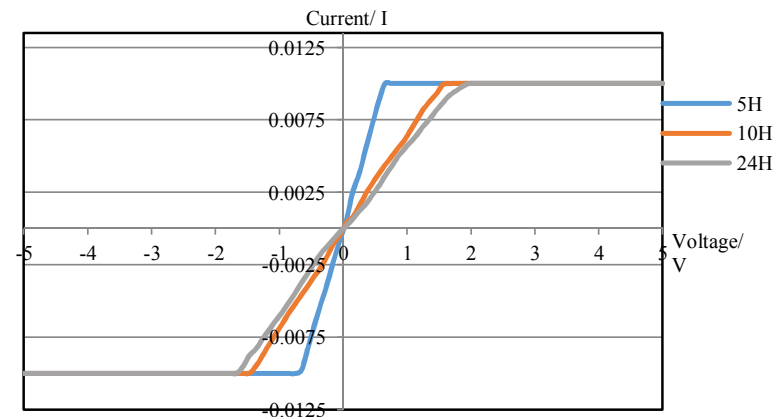

Figure 5: The variation of I-V gradient with the three different time duration hydrothermal synthesis (a) 5 hours, (b) 10 hours, (c) 24 hours. 
The resistance obtained from Fig. 5, the resistivity and the sheet resistance were summarized in Table 1. In the table, it was seen that the $5 \mathrm{~h}$ sample had the lowest resistance of $70.713 \Omega$ while $24 \mathrm{~h}$ sample had the highest resistance of $183.639 \Omega$. This proved that the resistance is associated with the deposited layer thickness. While for resistivity and sheet resistance, the data were obtained from the equations shown below:

Resistivity, $\rho$

$$
\rho=R_{s} \times t
$$

Sheet resistance, $\mathrm{R}_{\mathrm{s}}$

$$
\mathrm{R}_{\mathrm{s}}=\rho / \mathrm{t}
$$

Table 1: Electrical parameters of the nanostructured FTO thin films samples from 5 hours to 24 hours hydrothermal synthesis.

\begin{tabular}{|c|c|c|c|c|c|}
\hline No. & Sample & $\begin{array}{c}\text { Resistance, } \\
\mathrm{R}(\Omega)\end{array}$ & $\begin{array}{c}\text { Resistivity, } \\
\rho \times 10^{-3}\end{array}$ & $\begin{array}{c}\text { Sheet } \\
\text { Resistance, } \\
\mathrm{R}_{\mathrm{s}}\left(\Omega / \mathrm{cm}^{2}\right)\end{array}$ & $\begin{array}{c}\text { Average } \\
\text { Thickness, } \\
\mathrm{t}(\mathrm{nm})\end{array}$ \\
\hline 1 & $5 \mathrm{~h}$ & 70.713 & 18.49 & 176.783 & 1046 \\
\hline 2 & $10 \mathrm{~h}$ & 156.772 & 44.41 & 391.93 & 1133 \\
\hline 3 & $24 \mathrm{~h}$ & 183.639 & 1.771 & 550.917 & 3857 \\
\hline
\end{tabular}

\section{Optical properties}

The transmittance in the selected visible wavelength range corresponded to the time variation of hydrothermal synthesis was shown as in Fig. 6.

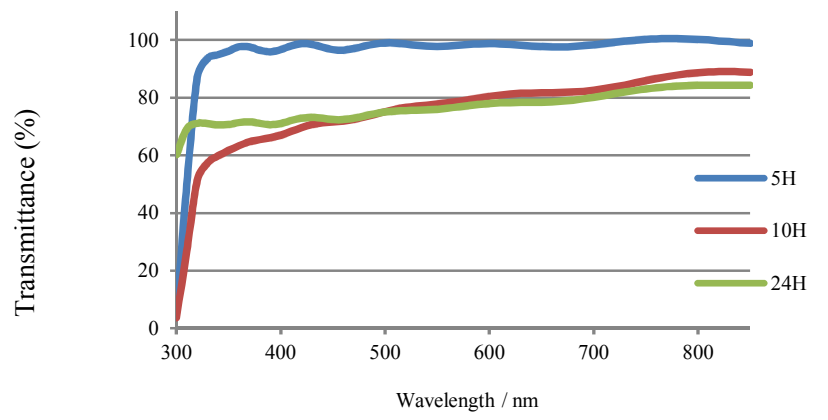

Figure 6: The transmittance of the nanostructured FTO thin film corresponding to the different time duration throughout the hydrothermal synthesis (a) $5 \mathrm{~h}$, (b) $10 \mathrm{~h}$, (c) $24 \mathrm{~h}$.

The oscillations in the visible region were due to the interference effects observed in FTO films. There were a considerable amount of decrement in the transparency of the samples as the time duration of hydrothermal synthesis increased from $5 \mathrm{~h}$ to $24 \mathrm{~h}$ which also led to the increment of the grain size of the nanostructured FTO thin film. In addition, the transmittance mainly depended on the film thickness, grain size, grain distribution and morphological structure. The sample fabricated for $5 \mathrm{~h}$ had the highest transmittance of about $90-95 \%$ at wavelength $550 \mathrm{~nm}$, while for $10 \mathrm{~h}$, it was about $75-80 \%$ transmittance and for $24 \mathrm{~h}$ was about $75-78 \%$ transmittance. For $24 \mathrm{~h}$, some milk spots were detected which might led to the decrement of the transmittance. This variation was also attributed to the variation in free carrier concentration. From the transmittance that have been obtained, the direct band gap of the FTO samples were determined as depicted in Table 2 where all the values were around the theoretical value of 3.3-4.0eV [16-17]. The bandgap of the samples decreased as the time duration of the hydrothermal synthesis increased which might due to the Burstein-Moss Shift [18].

Table 2: The time duration of hydrothermal synthesis versus the bandgap, $\mathrm{E}_{\mathrm{g}}$

\begin{tabular}{|r|l|c|}
\hline No & Sample & Bandgap, $\mathrm{E}_{\mathrm{g}}(\mathrm{eV})$ \\
\hline 1 & 5 hours & 3.882 \\
\hline 2 & 10 hours & 3.765 \\
\hline 3 & 24 hours & 3.55 \\
\hline
\end{tabular}




\section{Conclusion}

The FTO solution has been successfully synthesized by mixing $1.53 \mathrm{M} \mathrm{NH}_{4} \mathrm{~F}$ and $0.8 \mathrm{M} \mathrm{SnCl}_{4} .5 \mathrm{H}_{2} \mathrm{O}$ together with propyl alcohol solution as the solvent. The fabrication of nanostructured FTO thin film was done by varying the time duration during hydrothermal process. The UV-Vis study revealed that the transmittance decreased from $90 \%$ to $75 \%$ when the time duration was increased from $5 \mathrm{~h}$ to $24 \mathrm{~h}$. This was due to the better crystallized film and high transparency surface formed in shorter time duration. This result was supported by the FESEM characterization where the images shown that the seed layer formed on the FTO substrate increased with random grains distribution and the grain size growth increased as the time duration of hydrothermal process increased. The average grain sizes for $5 \mathrm{~h}, 10 \mathrm{~h}$ and $24 \mathrm{~h}$ samples were $310 \mathrm{~nm}, 465 \mathrm{~nm}$ and $500 \mathrm{~nm}$, respectively. The figure of merit of nanostructured FTO has minimum resistance $176.783 \Omega / \mathrm{cm}^{2}$ and over $80 \%$ for average transmittance. Another important finding of this research was different solution for hydrothermal synthesis could be made by preparing $0.1 \mathrm{M}$ DBTA where through FESEM characterization, nanocrytal growth was detected on the FTO crystal.

\section{Acknowledgements}

The authors would like to acknowledge Microelectronic and Nanotechnology Shamsuddin Research Center (MINT-SRC), Universiti Tun Hussein Onn Malaysia for providing laboratory apparatus and characterization equipment. This work was supported by FRGS Vote No. 1213.

\section{References}

[1] C. G. Granqvist, Solar Energy Materials and Solar Cells, 91(17), 2007, pp. 1529-1598.

[2] K. Elmer, Nature Photonics, 6(12), 2012, pp. 809-817.

[3] A. V. Moholkar, S. M. Pawar, K. Y. Rajpure, C. H. Bhosale, J. H. Kim, Applied Surface Science, 255(23), 2009, pp. 9358.

[4] A. A. Yadav, E. U. Masumdar, A. V. Moholkar, K. Y. Rajpure, C. H. Bhosale, Physica B: Condensed Matter, 404(12-13), 2009, pp. 1874-1877.

[5] K. Y. Rajpure, M. N. Kusumade, S. M. N. Neumann, C. H. Bhosale, Matter Chemistry and Physics, 64(3), 2000, pp. 184-188.

[6] K. Matsune, H. Oda, T. Toyama, H. Okamoto, Y. Kudriavysev, R. Asomoza, Solar Energy Materials and Solar Cells, 90(18-19), 2006, pp. 3108-3114.

[7] K. S. Shamala, L. C. S. Murthy, K. N. Rao, Bulletin of Materials Science, 27(3), 2004, pp. 295301.

[8] M. R. Khelladi, L. Mentar, M. Boubatra, A. Azizi, A. Kahoul, Material of Chemical Physics, 122(2-3), 2010, pp. 449-453.

[9] Z. Hong, J. Tao, W. Tao, J. Deng, Applied Surface Science, 257(24), 2011, pp. 10494-10498.

[10]A. V. Moholkar, S. M. Pawar, K. Y. Rajpure, C. H. Bhosale, Materials Letters, 61(14-15), 2007, pp. 3030.

[11]N. Y. Shishkin, I. M. Zharsky, V. G. Lugin, V. G. Zarapin, Sensors and Actuators B: Chemical, 48(1-3), 1998, pp. 403-408.

[12]Z. W. Chen, J. K. L. Lai, C. H. Shek, Physics Letters A, 345(1-3), 2005, pp. 218-223.

[13] T. H. Fanga, W. J. Chang, Applied Surface Science, 220(3), 2003, pp. 175-180.

[14]B. Sunandan, D. Joydeep, Science Technology and Advanced Material, 10(1), 2009, pp. 1-18.

[15]B. Liu, E. S. Aydil, Journal of the American Chemical Society, 131(11), 2009, pp. 3985-3990.

[16] A. N. Baneree, S. Kundoo, P. Saha, K. K. Chattopadhyay, Journal of Sol-Gel Science and Technology, 28 (0), 2003, pp. 105-110.

[17] S. Das, V. Jayaraman, Progress in Materials Science, 66 (0), 2014, pp. 112-255.

[18]H. Kim, R. C. Y. Auyeung, A. Pique, Thin Solid Films, 516(15), 2008, pp. 5052-5056. 